\title{
Reflections on culturally responsive teaching: Embedding theory into practices of instructional and behavioral support
}

\author{
Randall De Pry \\ Elaine Cheesman
}

Follow this and additional works at: https://digitalscholarship.unlv.edu/jpme

\section{Repository Citation}

De Pry, Randall and Cheesman, Elaine (2010) "Reflections on culturally responsive teaching: Embedding theory into practices of instructional and behavioral support," Journal of Praxis in Multicultural Education: Vol. 5: No. 1, Article 7.

DOI: $10.9741 / 2161-2978.1031$

Available at: https://digitalscholarship.unlv.edu/jpme/vol5/iss1/7

This Article is protected by copyright and/or related rights. It has been brought to you by Digital Scholarship@UNLV with permission from the rights-holder(s). You are free to use this Article in any way that is permitted by the copyright and related rights legislation that applies to your use. For other uses you need to obtain permission from the rights-holder(s) directly, unless additional rights are indicated by a Creative Commons license in the record and/ or on the work itself.

This Article has been accepted for inclusion in Journal of Praxis in Multicultural Education by an authorized administrator of Digital Scholarship@UNLV. For more information, please contact digitalscholarship@unlv.edu. 


\title{
Reflections on Culturally Responsive Teaching: Embedding Theory into Practices of Instructional and Behavioral Support
}

\section{Randall De Pry and Elaine Cheesman}

\begin{abstract}
This paper offers reflections on the embedding of culturally responsive teaching practices into Response-to-Intervention (RtI) and School-wide Positive Behavior Support (SW-PBS) models. These types of systemic change models are increasingly being adopted by schools to address academic achievement and to foster a positive school climate. Moreover, they hold promise for addressing the disproportionality that many students who are culturally and linguistically diverse students experience in our schools. Following a review of the existing literature on systemic change, three guiding principles are offered that demonstrate how culturally responsive teaching can be embedded into models of instructional and behavioral support.
\end{abstract}

Thousands of schools across the United States have adopted Response to Intervention (RtI) and School-wide Positive Behavior Support (SW-PBS) programs over the past decade. These models hold promise in helping educators implement research-based instructional and behavioral support strategies that are intended to meet the academic and social/behavioral needs of all learners. While more similar than different, each model has the potential for creating systemic change in schools that can result in improved academic and social outcomes. Proponents believe that this is especially true for students from culturally and linguistically diverse backgrounds who have experienced marginalization, including disproportionately higher rates of academic failure, placement in special education, suspensions, expulsions, and school dropout (Skiba et al., 2008). Scholars have cautioned that "if we do not engage in dialogue about how culture mediates learning, RTI models will simply be like old wine in a new bottle, in other words, another deficit-based approach to sorting children, particularly children from marginalized communities" (NCCRESt, 2005, p. 1).

The purpose of this paper is share reflections on the need for embedding culturally responsive teaching (CRT) into RtI and SW-PBS implementation efforts. The first section of this paper will provide a brief overview of RtI and SW-PBS highlighting similarities and providing examples from work being done in Colorado. Terms such as "Instructional Support" and "Behavioral Support" will be introduced and a new definition of Culturally Responsive Teaching that is more closely aligned to systemic change models is offered. The second part of the paper will highlight three guiding principles, gleaned from the extant literature, that can assist classroom teachers, 
administrators, and researchers who are looking for evidence-based strategies that can be used across a variety of educational settings that employ RtI and SW-PBS.

\section{Systemic Change in Schools}

Educational leaders now recognize that true educational reform starts by focusing on systemic change (see Sugai et al., 2000). RtI and SW-PBS models are an excellent example of this precept given their focus on instructional and behavioral systems. For example, the design of instruction (lesson planning, selection of the curriculum, developing guided and independent practice activities, evaluation procedures) and the delivery of instruction (differentiated instructional practices, multiple and varied opportunities to learn the material) focus on the teacher as the primary agent of change. Focusing on our behavior as adults (e.g., instructional behaviors, collaborative behaviors, personal attitudes and biases), instead of trying to attribute a within child explanation for academic or behavioral challenges is a critical first step toward systemic change (Gravois \& Rosenfield, 2006).

Another way that RtI and SW-PBS schools are engaging in systemic reform is to use scientifically validated instructional and behavioral support practices that are data driven. Data-based instructional practices allow the teacher to have frequent contact with relevant data to more fully understand the learning (or lack thereof) that is taking place and to systematically meet the diverse needs of all learners (Bushell \& Baer, 1994). As NCCRESt (2005) reminds us, all students need to have unequivocal opportunities to learn. In relation to culturally responsive practices within an RTI models, they write "Opportunity to learn is a complex construct that includes not only access to key resources (qualified teachers, funding, relevant and rigorous curriculum), but also factors related to the nature and implementation of school activities (e.g., culturally meaningful task criteria, teacher-student shared understandings of the purpose of tasks and activities, culturally inclusive participation frameworks in classroom discourse, school deficit ideologies about low-income racial minority students used in referral and placement practices)" (p. 1). In other words, contextual factors must align with the selection and implementation of scientifically validated instructional practices in order to support successful learning.

\section{Triangle of Support: An Integrative Model}

Figure 1 illustrates the "Colorado Triangle" which seeks to show the integration of academic and behavioral support. The triangle uses colors to illustrate how 
instructional and behavioral support is differentiated. Green, the largest part of the triangle, is viewed as a universal level of support. Examples of Tier 1 support include implementation of a school-wide reading program (see Biemiller, et al., 2008) or teaching three to five positively stated school-wide behavioral expectations that apply to all students, all staff, and across all settings (see Taylor-Green et al., 1997). Yellow, signifies that support is targeted to meet the unique needs of a smaller group of learners. Interventions are databased and tailored to the specific needs of the students. Examples of Tier 2 support include math instruction that is provided to a small group of students (see Woodward \& Strohl, 2006) or use of a Check-in Check Out program for students who need targeted behavioral support (see Todd, Campbell, Meyer, \& Horner, 2008). Red indicates that the level of support is more individualized and intensive. Decisions about implementation are based on multiple sources of data and are made by a school-based problem-solving team. Examples of Tier 3 support include individual or small-group instruction for students requiring intensive support in written composition (see Morgan, 2001) or implementation of a behavior intervention plan based on a comprehensive functional assessment (see O'Neill et al., 1997; Scott, Nelson, \& Zabala, 2003; Sugai et al., 2000). The Colorado Department of Education (2008) further describes each of the tiers and their relationship to instructional and behavioral support, stating:

Tier 1 refers to classroom instruction for all students. This universal level of instruction should meet the needs of at least $80 \%$ of the students. At this level all students are receiving research-based instruction that is high quality. Core instruction should be implemented with fidelity utilizing a curriculum that is viable, rigorous, relevant and standards-driven. Core instruction should also offer sufficient depth, breadth, and complexity to meet the needs of all students in a classroom. Tier I also includes universal supports that are available to all students in academics and behavior...Tier II includes individualized, targeted supports for students with more significant academic and/or behavior concerns or who have been identified as underachieving. If a student continues to demonstrate insufficient progress and the gap between the student's achievement and expected achievement increases, a more intensive intervention plan can be put in place with the assistance of the problem-solving team through data-driven dialogue...Tier III intensive supports are intended for students with significant and/or chronic deficits as well as for students with significant underachievement who require the most intensive services available in a school. Moving to a Tier III intervention is determined by the problem-solving team after several individualized interventions have resulted in limited progress, based on the achievement gap 
between the student's progress and the expected benchmark. The interventions in Tier III are skill specific interventions that can be delivered by a variety of providers. (pp. 11-13)

Finally, the Colorado triangle visually shows a blending of colors that suggests fluidity and movement based on student learning, growth, and response to intervention. It is important to remember that the focus is not on finding new ways to label students ("She is a yellow zone student"), but on matching the level and intensity of support to a demonstrated academic or behavioral need. Successfully linking assessment data to intervention planning is a critical outcome of the problem-solving process. Team-based problem solving is best understood as a collaborative effort (e.g., administrators, teachers, support personnel, parents, and ideally the student, see Martin, Marshall, \& De Pry, 2008) that seeks to understand the academic and/or social problem and identify support strategies that are evidenced-based, contextually relevant, and selected with success in mind. RtI models use this process to support teachers who have requested help, to identify and understand emerging data patterns, to develop research-based interventions, and to measure progress over time and across settings (Colorado Department of Education, 2008; Gravois \& Rosenfield, 2006; Rock \& Zigmond, 2001; Safran \& Safran, 1996).

\section{Family and Community Engagement}

Team-based problem solving encourages a databased dialogue, collaboration, and successful implementation of research-based instructional and behavioral supports. The Colorado Department of Education (2008) writes that "Family engagement in the process is vital to ensure all information that might impact success is considered" (p. 6). Including all critical stakeholders, such as family members, in the problem solving process is known as contextual fit (Albin, Lucyshyn, Horner, \& Flannery, 1996). When an intervention plan has good contextual fit, intervention planning has been carefully aligned to multiple perspectives and data source. Intervention plans that have good contextual fit are more likely to be implemented successfully because the time, values, beliefs, perspectives, and expertise associated with those who will be asked to implement the plan have been taken into account. As critical stakeholders, family and community members play a prominent role in Colorado's RtI implementations (see Figure 1). This is evident by the inclusion of family and community around the perimeter of the triangle of support. Adding family and community to the triangle aligns practice to the belief that academic achievement and social competence is functionally related to the school's ability to partner with families, caregivers, and community that results in positive and productive relationships (Ladson-Billings, 1995; Townsend, 2000). 
Figure 1

Colorado Multi-Tiered Models of Instruction and Intervention.

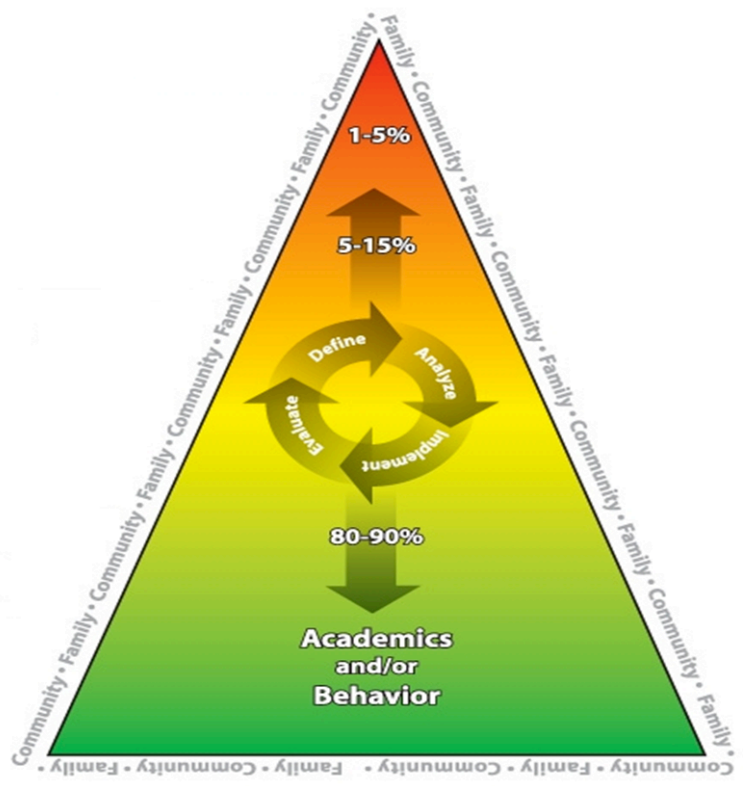

Used with permission, Colorado Department of Education

Given that RtI models purport to focus on systemic change, Klingner and Edwards (2006) remind us that a variety of societal influences impact schools and classrooms; therefore "a systems approach to reform that entails looking across multiple layers of the home, community, school, and society at large" is needed. They caution that "to conclude that failure resides within students when they do not progress with a certain intervention, and then move them onto the second or third tier in an RTI model or decide that they belong in special education without considering other factors, is problematic" (p. 112). When contextual fit is understood as aligning intervention planning to multiple perspectives and multiple forms of data across multiple systems (including school, home, and community), within-student explanations for academic and behavioral challenges will become less viable (Gravois \& Rosenfield, 2006). 


\section{From Management to Support}

RtI models focus on supporting students by managing systems. Systems include personnel, programs, practices, policies, procedures, and places within and outside of the educational setting. For example, SW-PBS is understood to have four interrelated systems that incorporate each of the descriptors listed above: (a) School-wide, which includes all settings, all staff, and all students; (b) Classroom, which is the primary place where academic instruction occurs; (c) Non-classroom, which are locations throughout the school that are less structured, such as hallways, cafeteria, and common school areas; and (d) Individual student, which focuses on students that have intensive individualized behavioral support needs (OSEP, 2004).

Without question, the word "support" is a prominent feature in SWPBS. This is a welcome change over the word "manage" which is so often used in the context of school-wide and classroom-based discipline models. Support suggests actions that are proactive, preventative, and instructional, versus reactive and punishment-oriented methods that are all too often applied to academic instruction and behavior management models. For purposes of this paper, the term "support" is also applied to teaching. In other words, the design and delivery of a continuum of academic practices is considered "Instructional Support". Figure 2 illustrates the interrelationship between instructional support, behavioral support, and embedded culturally responsive and evidence-based practices.

Experienced teachers know that teaching on a daily basis requires the combined use of instructional and behavioral supports to ensure success. For example, a universal approach to teaching reading might include a review of the behavioral expectation prior to instruction (behavioral support), use of a scientifically based reading program during instruction (instructional support), prompting correct responses and strategic use of positive reinforcement when the student responds correctly (behavioral support), and guided and independent practice opportunities to build fluency and continued learning (instructional support). In this example, the provision of support is determined by the educator and provided strategically based on student need. Students in this example received predominately instructional support with concomitant behavioral support (see Figure 3). On the other hand, a student who is struggling behaviorally is likely going to receive a higher measure of behavioral support (see Figure 4). Functional assessment data will guide the development of a comprehensive behavior intervention plan that will outline a variety of behavioral support strategies, including identifying a functionally equivalent replacement response that will make the problem behavior "irrelevant, ineffective, and inefficient" (O'Neill et al., 1997, p. 66). Noting the admonition 
Figure 2

Inter-relationship of instructional support, behavioral support, and embedded culturally responsive and evidence-based practices

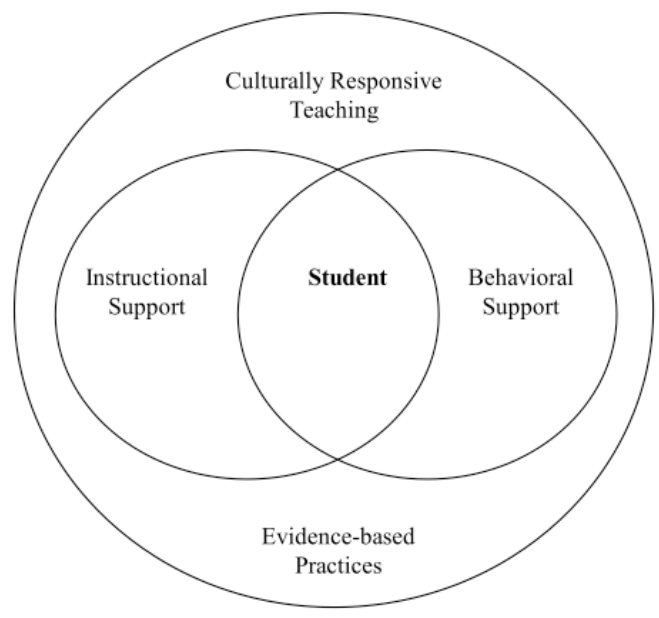

Figure 3

Focus on instructional support

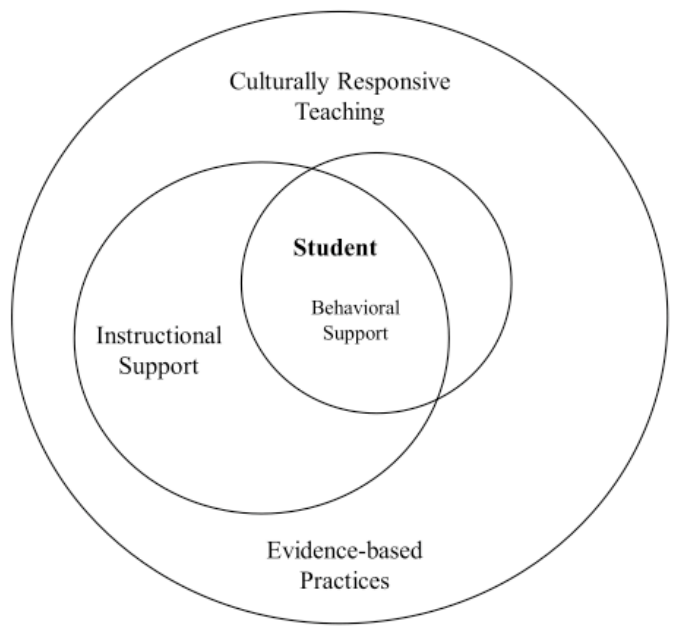


Figure 4

Focus on behavioral support

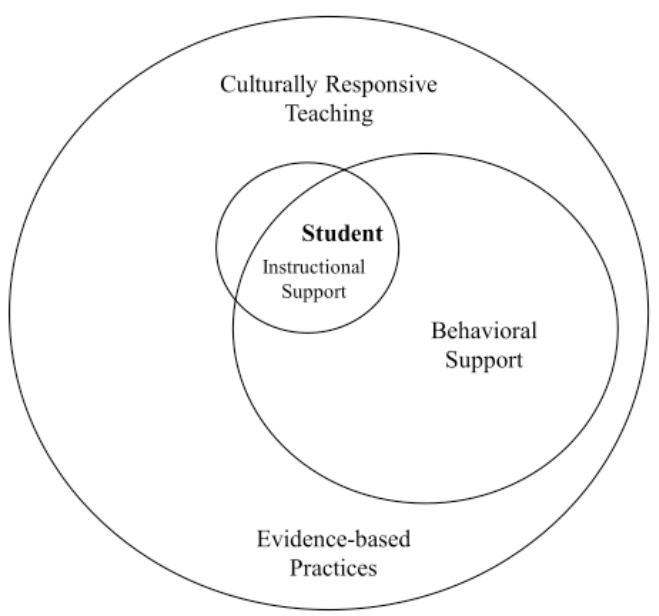

that "best time to intervene on problem behavior is when the behavior is not occurring" (Carr et al. 2002, p. 9) comprehensive behavioral support and concomitant instructional support must be carefully outlined and implemented with fidelity. Therefore, instead of viewing "academics" and "behavior" as separate entities, systems change models like RtI and SW-PBS view each as interrelated and the allocation of support is determined by student need (Fairbanks, Sugai, Guardino, \& Lathrop, 2007).

\section{Culturally Responsive Teaching and Systems Change}

Geneva Gay (2000) defines culturally responsive teaching as "using the cultural knowledge, prior experiences, and performance styles of diverse students to make learning more appropriate and effective for them; it teaches to and through the strengths of these students" (p. 29). As Skiba et al. (2008) notes, a comprehensive evaluation of culturally responsive practices should focus on positive academic and social outcomes; but as importantly, on the ability of those practices to reduce inequities such as disproportionality, drop-outs, and underachievement. Moreover, criteria outlined in Ladson-Billings (1995) that indicates that culturally relevant teaching must (a) develop the academic abilities of students, (b), promote and sustain cultural competence, and (c) develop the "sociopolitical or critical consciousness" are critical in developing a new 
definition of culturally responsive teaching that aligns with current systemic change efforts (p. 483). Therefore, for purposes of this paper, culturally responsive teaching is defined as recognition of the diverse backgrounds, knowledge, perspectives, experiences, and abilities that students, educators, and families bring to the culture of a school that result in the use of relevant, research-based instructional and behavioral support practices, which are implemented with intentionality, measured with fidelity, responsive to the needs of each learner, and systemically valued as a means of promoting equity and achievement for all students.

\section{Guiding Principles}

In reviewing the extant literature on culturally responsive teaching a number of guiding principles became evident that are presented below. These principles allow for the integration of instructional and behavioral supports within existing RtI models. Moreover, these practices, when embedded into RtI models will increase the likelihood that all learners will have access to evidence-based practices that lead to increased opportunities to learn and grow as students and individuals. OSEP (2004) indicates that priority is given to the "establishment of systems that support the adoption and durable implementation of evidence-based practices and procedures, and fit with and be part of on-going school reform efforts" (p. 14). This standard is used in the selection of guiding principles below.

\section{Effective Teaching is Culturally Responsive}

Effective teaching is foundational to instructional and behavioral support. This assertion seems obvious when applied to RtI, but it is equally as true when applied to PBS. School-wide PBS is an instructionally based model for teaching students new social responses that will enhance the overall school climate and set the occasion for academic engagement and achievement. Effective teaching has been a defined area of research for decades (Brophy \& Good, 1986; Ellis \& Worthington, 1994). For example, research evidence suggests that children who receive instruction that is explicit and systematic improve reading and writing skills at a faster rate and have higher skills than those who receive implicit or unstructured instruction (McCardle \& Chhabra, 2004; National Institute of Child Health and Human Development, 2000). Effectiveness, by definition, suggests that an intended outcome has been successfully met; however, a plethora of evidence exists that schools do not have the capacity to fully meet the instructional and behavioral support needs of all learners (Skiba et al., 2008; Townsend, 2000; Utley, Kozleski, Smith, \& Draper, 2002). Rigorous and 
systematic research must continue to identify instructional and behavioral support practices that are culturally responsive.

Effective teachers know their learners as they know themselves. To know your students requires a commitment to use academic data, as well as data on language, culture, gender, and other variables that bring understanding to the teaching/learning dynamic (Cartledge, Singh, \& Gibson, 2008). Effective teachers also take time to examine and reflect on their own teaching practices. Pearce (2005) provides an excellent example of one way to do this. As a classroom teacher Sarah Pearce maintained a diary that taught her much about herself, her students, and her own practice of teaching. She writes "keeping a diary is a well-understood process, and is both manageable and unobtrusive... it enables teachers to gain a degree of distance from their own thinking and behavior, so that they can understand, analyze and ultimately begin to change it. In other words, the diary enabled me to gain a sense of control over my teaching, and to consciously change some of my attitudes" (p. 5). Finally, effective teachers get to know students as individuals, versus solely studying group characteristics. This provides the teacher with critical information that is unique to that student and his or her life experiences and reduces problems associated with essentializing individual traits based on group membership (Gutierrez \& Rogoff, 2003).

The effective teaching cycle is a well understood method for designing and delivering instruction. The effective teaching cycle includes a review set, presentation of new content, guided practice, independent practice, and weekly/monthly review (Ellis \& Worthington, 1994; Rosenshine \& Stevens, 1986). While it is beyond the objective of this paper to fully review all aspects of effective teaching, one facet of the effective teaching cycle is worth mentioning. The review set is an opportunity for the teacher to activate prior learning and experiences, to create interest and motivation around the upcoming lesson, to help the students anticipate the content that will be presented, and to state the instructional objective for the lesson.

Given the obvious importance of the review set, about 15 to $20 \%$ of the allocated time for instruction is given to this lesson feature. This simple instructional practice is an excellent example of how to embed cultural responsiveness into typical lesson design and delivery. Through the judicious use of questioning, activities, and review, students begin to make important learning connections as they prepare for the content that will follow. In other words, effective teachers know how to make lessons relevant by assisting students in seeing the importance of the lesson in relation to their previous learning and experiences (see Gay, 2000; Ladson-Billings, 1995).

\section{Teach Respect: Model Caring}


Educators have historically valued the teaching of "respect" as a means of promoting relationships (teacher/student and student/student) and as a method for facilitating teaching and learning. Respect, by definition, is relational, meaning that the focus is primarily on how we treat each other. Given that perspective, it is not hard to understand why respect is one of the more common school-wide behavioral expectations selected by PBS teams. Defining and teaching three to five positively stated behavioral expectations that apply to all students, all staff, and across all settings is central to the successful implementation of SW-PBS (De Pry, 2007; OSEP, 2004). However, as Utley, Kozleski, Smith, and Draper (2002) remind us, "For culturally relevant PBS to be realized, professionals, families, and students must all wrestle with achieving interactive, participatory norm setting and re-setting to ensure that one cultural perspective does not dominate the rule making, the norm setting, and the curriculum" (p. 205). Like behavioral expectations, the teaching of social skills is also seen as critical, particularly for students with challenging behavior. Social skills associated with respect (e.g., joining and working in groups, sharing opinions, greeting those you meet, maintaining boundaries) are prosocial alternatives to problem behavior and may result in increases in positive relationships and academic performance (Cartledge, Singh, \& Gibson, 2008) as part of a culturally responsive framework for promoting prosocial conduct.

The teaching of school-wide behavioral expectations has many benefits. Taylor-Green et al. (1997) reported a 42\% reduction in office discipline referrals when her school adopted a school-wide model of PBS. As part of their model, they taught and practiced five positively stated behavioral expectations at the beginning of the school year. One of those expectations was related to respect. Taylor-Green et al. write "Faculty defined how each of the five expectations translated into specific behavior in each of the six main school locations. For example, 'be respectful' in the classroom involved listening to others without interrupting, 'be respectful' in the gym involved sharing equipment and space, 'be respectful' in the criteria involved waiting in line and speaking in a reasonable voice volume" (p. 103). By reducing the number of behavioral incidents that educators needed to respond to on a daily basis, the teaching team had more time for instruction and meaningful activities that promote learning and community.

Respect can quickly move from being a positive expectation to a compliance-oriented demand. For example, Townsend (2000) indicates that in suburban schools, teacher statements are often different than in inner city schools. In the former, statements tend to be academically focused, whereas in inner city schools, statements are more likely to be management-oriented. As noted earlier, management is often interpreted as a reactive stance, where support is proactive and preventative and illustrated above by Taylor-Green et al. (1997). Countering the compliance-only orientation for respect is critical for 
schools that seek to become culturally responsive. Utley, Kozleski, Smith, and Draper (2002) concludes that "Successful PBS programs for urban, multicultural students require cultural sensitivity, caring and respectful relationships between teachers and students, and a nurturing school environment to create learning communities in schools" (p. 202).

Gay (2000) suggests that caring educators are (a) genuinely concerned about their students and their students' learning; (b) respectful in how they communicate their expectations that promote action and accountability; (c) emotionally warm, yet requiring high levels of performance from all learners; and (d) cognizant of the teaching/learning dynamic and committed toward partnering with their students to achieve academic success for all. Effective teachers know that teaching students to be respectful helps to create learning environments that support teaching and student achievement (Cartledge, Singh, \& Gibson, 2008); as importantly, effective teachers model respect by caring for their students and providing instructional and behavioral support that promotes academic achievement, the development of interpersonal relationships, and prosocial conduct throughout the school day.

\section{Problem Resolution: Not Problem Students}

The inability of schools to fully address academic and social/behavioral "problems" is at the crux of issues related to disproportionate disciplinary practices, referrals to special education, and school dropout. Too often, educators view the student as the problem instead of examining systemic variables. Problem-solving teams may be one solution to this issue. Problemsolving teams have gone by many names over the years, examples include: Prereferral Teams, Intervention Assistance Teams, Student Support Teams, Instructional Support Teams, to name a few. All seem to operate following a similar pattern (a) to establish a problem-solving process and assist teachers, (b) to implement general education "solutions" prior to referral to special education, (c) to screen students for special education, and (d) to support teachers who work with students on Individualized Education Plans (IEPs) (Rock \& Zigmond, 2001). Team composition can include an administrator, general education and special education teachers, and other support personnel, such as a school psychologist or school counselor. As indicated earlier, the Colorado model actively encourages family involvement as part of this process (Colorado Department of Education, 2008).

Data on the effectiveness of Problem-solving Teams is mixed. Safran and Safran (1996) reported that an apparent gap exists between university demonstration projects (which showed positive effects) and data from actual practice in schools. Data reported by Rock and Zigmond (2001) found disproportionate referrals of African-American students in 5 out of the 9 schools they studied. The authors concluded that "students in this study who were African American were more likely to be referred and deemed eligible for 
special education services than students who were Caucasian. Although intervention assistance practices have been recommended as one strategy to combat over-identification of minority children, in this study they mirrored rather than eliminated the racial inequalities experienced during the traditional referral process" (p. 157).

Research conducted by Gravois and Rosenfield (2006) offers important insights that can inform current implementation efforts in RtI and SW-PBS schools. Their model for problem solving is called Instructional Consultation Teams (ICT). They assert that "the quality of instruction and intervention into learning problems influences whether students are ultimately referred for and placed in special education, regardless of race" (p. 44). In other words, this approach focuses on instructional consultation around content and processes by supporting teachers around the design and delivery of effective instruction and by engaging in problem solving in the general education setting. The requesting teacher is assigned a case manager (sometimes referred to as a coach in SWPBS) and regularly receives consultation around instructional design and delivery, as well as problem solving strategies.

By focusing on instructional consultation as part of the problemsolving process, special education placements for all students dropped when compared to control schools. Gravois and Rosenfield (2006) conclude that more emphasis should be placed on the role that instruction plays in special education referrals and placements and that this perspective "deserves an equal--if not central--focus in addressing disproportionality" (p. 49). These data provide additional support for systemic change efforts that focuses on the quality of instructional and behavioral supports and the role of collaboration as part of a problem-solving process. Gravois and Rosenfield conclude:

They found that whereas teachers' initial descriptions of their concerns were largely framed around the student as the source of the problem (i.e., internal student deficit), over the course of the instructional consultation process, teachers were able to re-frame the problem to include the influence that instructional variables had on student learning outcomes. In essence, the teachers did not just adopt strategies to help a student with a presumed disability; instead, they adopted strategies because they gained an understanding that instructional practices in and of themselves could promote or hinder student learning. This 'alternative hypothesis' of the underlying cause of student learning problems represents a fundamental shift in how teachers view both student learning and the influence on their own instructional practices. It also has important implications for forming hypotheses about the causes of disproportionate placements of minority students in special education and the resulting solutions to the problem. (p. 49)

\section{Conclusions}


RtI models seek to implement research-based instructional and behavioral support strategies in a manner that promotes systemic change in schools. An examination of data over the past several decades suggests that systems change will likely be difficult due a variety of competing influences, including hegemony and social dominance (Howard, 2006). Yet, these same data provide compelling reasons for engaging in systemic reform. As Klingner and Edwards (2006) indicate "RtI models hold promise for preventing academic failure by providing support for culturally and linguistically diverse students before they underachieve" (p. 108).

This paper examined specific features of RtI models and reflected on a new definition of culturally responsive teaching that takes into account a systemic change framework. Guiding principles were offered that focus on the central role that teaching, caring, and problem resolution can have on the disproportionate representation of culturally and linguistically diverse learners in our schools. It is our belief that by focusing primarily on adult behaviors, seeking contextual fit during intervention planning and implementation, and engaging in a data-based dialogue that results in multiple forms of information that guide our practices, that cultural responsiveness will be seen as one of the significant outcomes of RtI models. More importantly, our schools will begin to develop the capacity to meet the diverse academic and social/behavioral needs of all learners; and in so doing nurture the tremendous promise that each student brings to our schools through the implementation of culturally responsive instructional and behavioral support strategies.

\section{References}

Albin, R. W., Lucyshyn, J. M., Horner, R. H., \& Flannery, K. B. (1996). Contextual fit for behavioral support plans: A model for "Goodness of Fit". In L. K. Koegel, R. L. Koegel, \& G. Dunlap (eds.). Positive behavioral support: Including people with difficult behavior in the community. Baltimore, MD: Paul Brookes.

Biemiller, A., Campione, J., Carruthers, I., Fuchs, D., Fuchs, L., Graham, S., et al. (2008). Imagine It! Desoto, TX: SRA/McGraw-Hill.

Brophy, J. E., \& Good, T. L. (1986). Teacher behavior and student achievement. In M. C. Wittrock (Ed.), Handbook of research on teaching (3rd. ed.). New York: Macmillan.

Bushell, Jr., D., \& Baer, D. M. (1994). Measurably superior instruction means close, continual contact with the relevant outcome data. Revolutionary! In R. Gardner III, D. M. Sainato, J. O. Cooper, T. E. Heron, W. L. Heward, J. Eshleman. \& T. A. Grossi (Eds.), Behavior analysis in education: Focus on measurably superior instruction. Belmont, CA: Brooks/Cole. 
Carr, E. G., Dunlap, G., Horner, R. H., Koegel, R. L., Turnbull, A. P., Sailor, W., . . Fox, L. (2002). Positive behavior support: Evolution of an applied science. Journal of Positive Behavior Interventions, 4, 4-16, 20.

Cartledge, G., Singh, A., \& Gibson, L. (2008). Practical behavior-management techniques to close the accessibility gap for students who are culturally and linguistically diverse. Preventing School Failure, 52(3), 29-38.

Colorado Department of Education (2008). Response to intervention (RtI): A practitioner's guide. Denver, CO: Colorado Department of Education.

De Pry, R. L. (2007). Positive behavioral support. In C. R. Reynolds \& E. FletcherJanzen (Eds.), Encyclopedia of special education: A reference for the education of children, adolescents, and adults with disabilities and other exceptional individuals (3rd ed., pp. 1598-1600). Hoboken, NJ: John Wiley and Sons.

Ellis, E. S., \& Worthington, L. A. (1994). Research synthesis on effective teaching principles and the design of quality tools for educators. Retrieved from ERIC database. (ED386853)

Fairbanks, S., Sugai, G., Guardino, D., \& Lathrop, M. (2007). Response to intervention: Examining classroom behavior support in second grade. Exceptional Children, $73,288-310$

Gay, G. (2000). Culturally responsive teaching: Theory, research, \& practice. New York: Teachers College Press.

Gravois, T. A., \& Rosenfield, S. A. (2006). Impact of instructional consultation teams on the disproportionate referral and placement of minority students in special education. Remedial and Special Education, 27, 42-52.

Gutierrez, K. D., \& Rogoff, B. (2003). Cultural ways of learning: Individual traits or repertoires of practice. Educational Researcher, 32, 19-25.

Howard, G. R. (2006). We can't teach what we don't know: White teachers, multiracial schools (2nd ed.). New York: Teachers College Press.

Klingner, J. K., \& Edwards, P. A. (2006). Cultural considerations with response to intervention models. Reading Research Quarterly, 41, 108-117.

Ladson-Billings, G. (1995). Toward a theory of culturally relevant pedagogy. American Educational Research Journal, 32, 465-491.

Martin, J. E., Marshall, L. H., \& De Pry, R. L. (2008). Participatory decision-making: Innovative practices that increase student self-determination. In R. W. Flexer, T. J. Simmons, P. Luft, \& R. Baer (Eds.). Transition planning for secondary students with disabilities (3rd ed., pp. 340-366). Columbus: Merrill.

McCardle, P., \& Chhabra, V. (Eds.). (2004). The voice of evidence in reading research. Baltimore, MD: Paul H. Brookes Publishing Co.

Morgan, C. G. (2001). When they can't write. Richmond, VA: York Press.

National Institute of Child Health and Human Development. (2000). Report of the National Reading Panel. Teaching children to read: An evidence-based assessment of the scientific research literature on reading and its implications for reading instruction. Washington, DC: U.S. Government Printing Office.

NCCRESt (2005). Cultural considerations and challenges in response-to-intervention models: An NCCRESt position statement. Retrieved from http://www.nccrest.org/PDFs/rti.pdf?v_document_name=Culturally\%20Respon sive $\% 20$ RTI 
O’Neill, R. E., Horner, R. H., Albin, R. W., Sprague, J. R., Storey, K., \& Newton, J. S. (1997). Functional assessment and program development for problem behavior: A practical handbook (2nd ed.). Pacific Grove, CA: Brooks/Cole.

OSEP Center on Positive Behavioral Interventions and Supports (2004). School-wide positive behavior support: Implementers' blueprint and self-assessment. University of Oregon: OSEP Center on Positive Behavioral Interventions and Supports.

Pearce, S. (2005). You wouldn't understand: White teachers in multiethnic classrooms. Sterling, VA: Trentham Books.

Rock, M. L., \& Zigmond, N. (2001). Intervention assistance: Is it substance or symbolism? Preventing School Failure, 45, 153-161.

Rosenshine, B., \& Stevens, R. (1986). Teaching functions. In M. C. Wittrock (Ed.), Handbook of research on teaching (3rd. ed.). New York: Macmillan.

Safran, S. P., \& Safran, J. S. (1996). Intervention assistance programs and prereferral teams: Directions for the twenty-first century. Remedial and Special Education, 17, 363- 369.

Scott, T. M., Nelson, C. M., \& Zabala, J. (2003). Functional behavior assessment training in public schools: Facilitating systemic change. Journal of Positive Behavior Interventions, 5, 216-224.

Skiba, R. J., Simmons, A. B., Ritter, S., Gibb, A. C., Rausch, M. K., Cuadrado, J., \& Chung, C.G. (2008). Achieving equity in special education: History, status, and current challenges. Exceptional Children, 74, 264-288.

Sugai, G., Horner, R. H., Dunlap, G., Hieneman, M., Lewis, T. J., Nelson, C. M., . . .Ruef, M. (2000). Applying positive behavior support and functional behavioral assessment in schools. Journal of Positive Behavior Interventions, 2, 131-143.

Taylor-Greene, S., Brown, D., Nelson, L., Longton, J., Gassman, T., Cohen, J.,...Hall, S. (1997). School-wide behavioral support: Starting the year off right. Journal of Behavioral Education, 7, 99-112.

Todd. A. W., Campbell, A. L., Meyer, G. G., \& Horner. R. H. (2008). The effects of a targeted intervention to reduce problem behaviors: Elementary school implementation of Check In-Check-Out. Journal of Positive Behavior Interventions, 10, 46-55.

Townsend, B. L. (2000). The disproportionate discipline of African American learners: Reducing school suspensions and expulsions. Exceptional Children, 66, 381391.

Utley, C. A., Kozleski, E., Smith, A., \& Draper, I. L. (2002). Positive behavior support: A proactive strategy for minimizing behavior problems in urban multicultural youth. Journal of Positive Behavior Interventions, 4, 196-207.

Woodward, J., \& Strohl, M. (2006). Transitional mathematics (2nd ed.). Longmont, CO: Sopris West Educational Services. 